\title{
Secretome proteomics reveals candidate non-invasive biomarkers of BRCA1 deficiency in breast cancer
}

\author{
Marc Warmoes ${ }^{1, *}$, Siu W. Lam ${ }^{1, *}$, Petra van der Groep ${ }^{2,3}$, Janneke E. Jaspers ${ }^{4,5}$, \\ Yvonne H.C.M. Smolders ${ }^{2}$, Leon de Boer ${ }^{1}$, Thang V. Pham ${ }^{1}$, Sander R. Piersma ${ }^{1}$, \\ Sven Rottenberg ${ }^{5,6}$, Epie Boven ${ }^{1}$, Jos Jonkers ${ }^{4}$, Paul J. van Diest ${ }^{2}$, Connie R. \\ Jimenez ${ }^{1}$ \\ ${ }^{1}$ Oncoproteomics Laboratory, Department of Medical Oncology, VU University Medical Center, Amsterdam, The Netherlands \\ ${ }^{2}$ Department of Pathology, University Medical Center Utrecht, Utrecht, The Netherlands \\ ${ }^{3}$ Department of Internal Medicine, University Medical Center Utrecht, Utrecht, The Netherlands \\ ${ }^{4}$ Division of Molecular Oncology, The Netherlands Cancer Institute, Amsterdam, The Netherlands \\ ${ }^{5}$ Division of Molecular Pathology, The Netherlands Cancer Institute, Amsterdam, The Netherlands \\ ${ }^{6}$ Institute of Animal Pathology, Vetsuisse Faculty, University of Bern, Bern, Switzerland \\ *These authors contributed equally to this work
}

Correspondence to: Connie R. Jimenez, email: c.jimenez@vumc.nl

Keywords: proteomics, biomarkers, BRCA1, breast cancer

Received: May 11, 2016 Accepted: August 13, $2016 \quad$ Published: August 23, 2016

\section{ABSTRACT}

Breast cancer arising in female BRCA1 mutation carriers is characterized by an aggressive phenotype and early age of onset. We performed tandem mass spectrometry-based proteomics of secretomes and exosome-like extracellular vesicles from BRCA1-deficient and BRCA1-proficient murine breast tumor models to identify extracellular protein biomarkers, which can be used as an adjunct to current diagnostic modalities in patients with BRCA1-deficient breast cancer. We identified 2,107 proteins, of which 215 were highly enriched in the BRCA1-deficient secretome. We demonstrated that BRCA1-deficient secretome proteins could cluster most human BRCA1- and BRCA2-related breast carcinomas at the transcriptome level. Topoisomerase I (TOP1) and P-cadherin (CDH3) expression was investigated by immunohistochemistry on tissue microarrays of a large panel of 253 human breast carcinomas with and without BRCA1/2 mutations. We showed that expression of TOP1 and CDH3 was significantly increased in human BRCA1-related breast carcinomas relative to sporadic cases $(p=0.002$ and $p<0.001$, respectively). Multiple logistic regression showed that TOP1 (adjusted odds ratio [OR] 3.75; 95\% confidence interval [95\% CI], $1.85-7.71, p<0.001$ ) as well as CDH3 positivity (adjusted OR 2.45; 95\% CI, $1.08-5.49, p=0.032$ ) were associated with BRCA1/2-related breast carcinomas after adjustment for triple-negative phenotype and age. In conclusion, proteome profiling of secretome using murine breast tumor models is a powerful strategy to identify non-invasive candidate biomarkers of BRCA1-deficient breast cancer. We demonstrate that TOP1 and CDH3 are closely associated to BRCA1-deficient breast cancer. These data merit further investigation for early detection of tumors arising in BRCA1 mutation carriers.

\section{INTRODUCTION}

Approximately $5-10 \%$ of female breast cancer are believed to be hereditary, caused by a germline mutation in the $B R C A 1$ or $B R C A 2$ genes. Owing to an increased lifetime cancer risk and young age of onset, mutation carriers are eligible for an intensified surveillance program consisting of clinical breast examination and 
annual screening mammography with the intention to detect breast cancer at a potentially curable stage. The accuracy of screening mammography to detect early breast lesions is, however, limited in young women due to their dense breast tissue [1-3]. Magnetic resonance imaging as an adjunct to screening mammography has improved sensitivity to detect suspected breast lesions [4, 5], but interval breast cancer rates remain substantial and specificity is limited [6]. There is therefore a compelling need to improve current clinical management i.e. early breast cancer detection in $B R C A$ mutation carriers.

Tumor cell-secreted proteins, constituting the secretome, have been proposed as biomarkers potentially detectable in the blood circulation or other body fluids [7]. Proteomic profiling of cancer secretomes from genetically engineered mouse models (GEMMs) with tissue-specific deletion of targeted genes may point towards relevant proteins, that are closely associated with the altered gene. For example, employing proteomic analysis on conditional GEMMs for BRCA1-deficient and -proficient breast tumors, we have previously identified a tissue-specific signature of 45 proteins, that can discriminate human $B R C A 1$ - and BRCA2-deficient breast carcinomas from other familial or sporadic breast carcinomas [8-10]. The question remains whether this signature is applicable for routine clinical assessment, but our findings, together with other reports, underscore the usefulness of GEMMs and the potential of proteomics as an approach for discovery of novel protein biomarkers.

In the current study, we applied an in-depth proteomic profiling of secretomes and extracellular vesicles (EVs) of BRCA1-deficient and -proficient breast tumor cell lines derived from three validated GEMMs. Comparative analysis revealed that BRCA1 deficiency has a marked effect on the repertoire of released proteins. Moreover, the majority of these proteins has been shown to be detectable in human plasma, indicative of their potential as blood-based markers. As a first step to evaluate clinical relevance, we analyzed protein expression of topoisomerase I (TOP1) and P-cadherin (CDH3) in a large panel of breast cancer tissues from $B R C A 1 / 2$ mutation carriers and women without a hereditary predisposition. We report that TOP1 and $\mathrm{CDH} 3$ were expressed to a higher extent in BRCA1-related breast carcinomas relative to sporadic breast carcinomas, highlighting their potential clinical usefulness for breast cancer detection in women with a $B R C A 1$ mutation.

\section{RESULTS}

\section{Protein profiling of $B R C A 1$-deficient and -proficient breast tumor cell line secretomes}

For this study, we used primary mammary tumor cell lines derived from a well-characterized GEMM for BRCA1-deficient breast cancer (K14Cre; $\mathrm{BrCa}^{-/-} ; \mathrm{p53}^{-/-}$) and from two different GEMMs for BRCA1-proficient breast cancer (K14Cre;p53 $3^{-/-}$and $\mathrm{K} 14 \mathrm{Cre} ; \mathrm{Cdh}^{-/-} ; p 53^{-/-}$). To identify secreted proteins potentially associated with $B R C A 1$ deficiency, we analyzed secretomes (in biological triplicate for each cell line) using a robust and reproducible label-free proteomics workflow $[8,11]$ as shown in Figure 1. Reproducibility of protein identification and quantification from biological triplicate experiments was high (an overlap of identified proteins of $>80 \%$ and the coefficient of variation of $14-15 \%$ of the overlapping proteins across triplicate experiments of each group, Supplementary Figure 1A).

A total of 2,107 proteins were identified in at least one of nine secretome samples. A large proportion of proteins $(59 \%)$ was predicted to be secreted via classical (24-32\%) or non-classical (29-33\%) secretory pathways as determined with SignalP and SecretomeP (Supplementary Figure 2 and Supplementary Table 1). Of 2,107 proteins, 1,365 proteins were commonly identified among the three cell lines (in at least one triplicate, see Supplementary Figure 1B). Unsupervised hierarchical clustering analysis on all proteins demonstrated a distinct separation between $B R C A 1$-deficient and $B R C A 1$-profient groups indicating that the proteomic portrait of secretome may be influenced by the $B R C A 1$ gene knockout status (Supplementary Figure 3).

A total of 912 significantly differentially released proteins between $B R C A 1$-deficient and $B R C A 1$-proficient secretomes were identified. Of these, 509 proteins were more abundantly present in BRCA1-deficient secretomes, whereas 403 proteins were less abundantly released (Supplementary Table 1).

\section{Murine BRCA1-deficient proteins in human $B R C A 1 / 2$-mutated breast cancer}

To examine human relevance, we analyzed the 509 upregulated BRCA1-deficient proteins in an mRNA dataset as published by Jönsson et al. [12]. This dataset contains 359 patients with breast cancer, among which there were 22 BRCA1 mutation cases, 32 BRCA2 mutation cases and 305 sporadic cases. Among the upregulated $B R C A 1$-deficient proteins, 254 proteins could be mapped to the corresponding mRNA transcript levels. Hierarchical cluster analysis showed that the mapped mRNA transcripts could separate the majority of the BRCA1/2-deficient breast carcinomas from the majority of sporadic breast carcinomas (Figure 2). A total of 50 mRNA transcripts were also overexpressed in $B R C A 1 / 2$-deficient breast cancer relative to sporadic breast cancer $(p<0.1$, Supplementary Table 2). These included chromatin remodeling proteins including SMC2, SMC1A, TOP2A, DNMT1 and DEK. Two candidates, namely SMC1A and TOP2A, were part of our previously identified 45 proteins BRCA-like tissue signature [8]. Although protein abundance and mRNA expression may not consistently correlate because of e.g. 
post transcriptional regulation, our findings suggest that proteins highly released by $B R C A 1$-deficient breast cancer cell line, when mapped to mRNA transcript, may enrich $B R C A 1 / 2$-related breast cancer.

\section{Selection of candidate non-invasive $B R C A 1$ - deficiency breast tumor biomarkers and in silico exploration of their connectivity and biological functions}

To reduce the list of differentially released proteins to the most discriminatory ones, we applied more stringent selection criteria $(p<0.01$, fold change $>5$ and total spectral count of $\geq 6$ in biological triplicates), resulting in 215 proteins highly enriched in the $B R C A 1$ deficient secretome and 100 proteins highly enriched in the BRCA1-proficient secretome (Supplementary Table 2). Interestingly, the proportion of nuclear proteins was higher in these $215 B R C A 1$-deficient proteins compared to that in the $100 \mathrm{BRCA1}$-proficient proteins (25 vs $14 \%$, Supplementary Figure 4).

To explore the connectivity and biological functions of the 215 highly discriminatory BRCAl-deficient proteins, we used the STRING tool in conjunction with gene ontology (GO) analysis. Detailed GO results are shown in Supplementary Table 3. This analysis yielded one large network of 155 proteins that consisted of seven regions of densely connected proteins (nodes) using the ClusterViz tool (minimum size of five proteins, Figure 3). These sub-networks were associated with the following biological processes as determined by BinGO analysis: 1. "multi-cellular organismal process" with subterms "angiogenesis" and "cell surface receptor-linked signaling pathway"; 2."chromosome organization" and "nucleic acid metabolic process" including the BRCAlike signature protein TOP1, a protein involved in DNA topological processes, and nucleophosmin (NPM1), a protein functionally associated with BRCA1-deficient double-stranded DNA repair; 3. "RNA processing" and "RNA splicing", including PRPF8 and SMC1A, that are both part of the previously published 45 protein BRCAlike tissue signature; 4. "metabolic process" with subterms "fatty acid metabolic process" and "lipid metabolic process"; 5. a cluster centered around protein translation with five out of eight proteins involved in the biological process "translation" (more specifically in "translational elongation") and three in "regulation of translation"; 6 . "carbohydrate metabolic process"; 7. this cluster had no clear association with any biological processes, but two

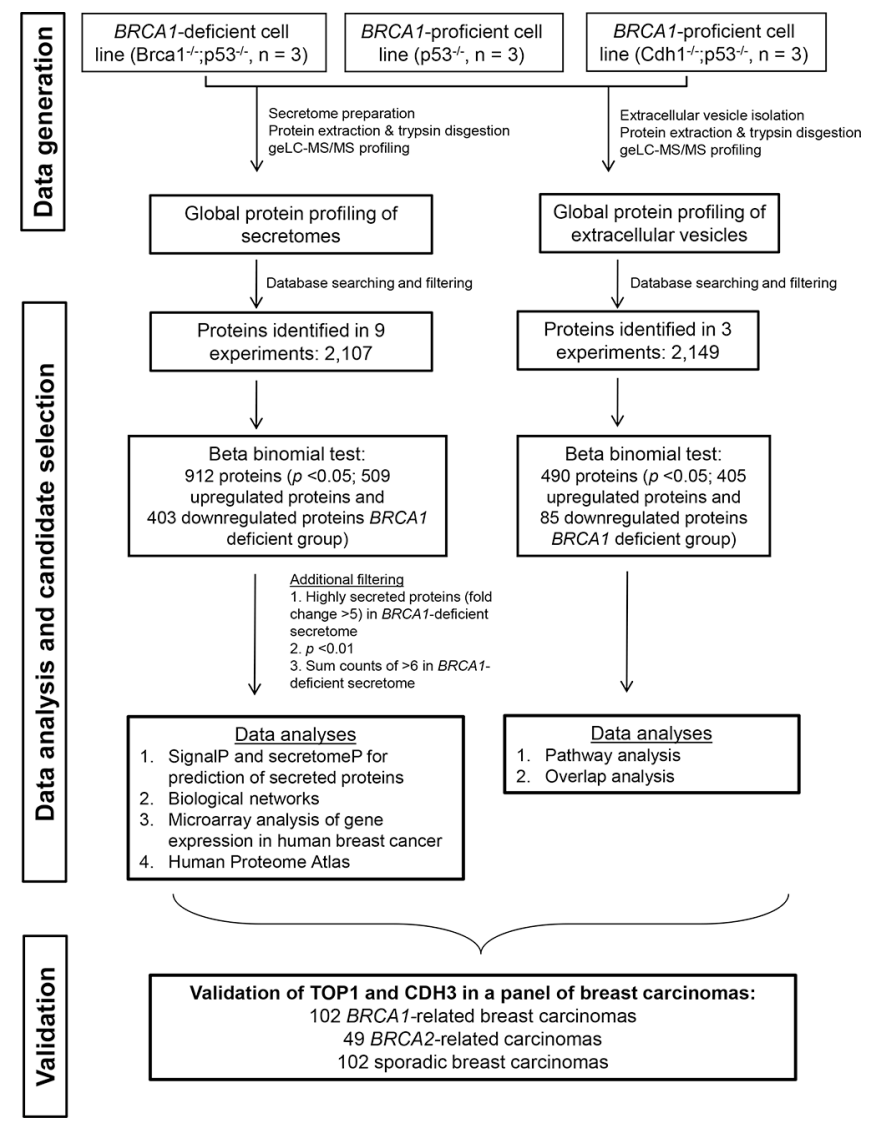

Figure 1: Experimental workflow to identify and validate $\boldsymbol{B} \boldsymbol{R} \boldsymbol{C A} \mathbf{1}$ deficiency protein biomarkers. The discovery experiment included three groups consisting of one BRCA1-deficient model and two BRCA1-proficient models, with three animals in each group. 
proteins, HYOU1 and HSP90B1, are involved in response to hypoxia (Figure 3).

The network of the 100 proteins highly abundantly released in BRCA1-proficient secretome is shown in Supplementary Figure 5 and contains three sub-networks associated with "metabolic process", "cell adhesion" and "cellular component movement".

In conclusion, the 215 proteins highly enriched in the $B R C A 1$-deficient secretome are involved in cellcell contact and communication, chromatin processes, RNA processing, protein translation and include several proteins that have been linked to $B R C A 1$-deficient breast cancer. $B R C A 1$-proficient cells release far less proteins and comprise a limited and totally different set of functions.

\section{Human plasma proteome}

We integrated the 215 highly abundant proteins of the BRCA1-deficient secretome into the public database of the human plasma proteome. Among these proteins, 162 (75\%) were identified in plasma (Supplementary Table 2). This in silico analysis indicated the potential of most proteins to enter the blood circulation and may assist in prioritizing candidate markers for future studies.

\section{Exosome-like EVs as carriers of BRCA1-deficient proteins}

As mentioned above, many proteins detected in the secretomes were predicted to be non-classically secreted.
Among them, a large proportion was of nuclear origin. This observation prompted us to explore whether these proteins might be released via the non-classical, vesiclemediated secretory pathway. Therefore, we performed proteomics of EVs isolated from the same BRCA1deficient and $B R C A 1$-proficient breast tumor cell lines resulting in 2,149 proteins (Supplementary Figure 6 and Supplementary Table 4). Exosomes are a class of EVs of endosomal origin. Multiple exosome-associated proteins were present and most proteins, including Alix, Tsg101 and CD63, were highly enriched in the EV fraction relative to the soluble secretome fraction (Figure 4A). Exosome enrichment was also confirmed by Western blot analysis of Alix (Figure 4B). The key biological processes (protein transport and vesicle-mediated transport) and molecular functions (GTP and ribonucleotide binding) were in line with the presence of several Rab GTases, known to be involved in vesicle formation, trafficking and transport [13] (Supplemental Figure 7).

A preliminary comparison of $\mathrm{EV}$ proteomes between BRCA1-deficient and -proficient groups identified 490 differentially abundant proteins. A total of 405 proteins were enriched in BRCA1-deficient vesicles. Major biological pathways of these $405 B R C A 1$-deficient proteins included DNA replication, RNA degradation and RNA splicing (Supplementary Figure 8).

A relatively large number of nuclear proteins was present among the $405 B R C A 1$-deficient proteins (Supplementary Figure 9). Overlap analysis revealed that 111 proteins were upregulated in the $B R C A 1$-deficient

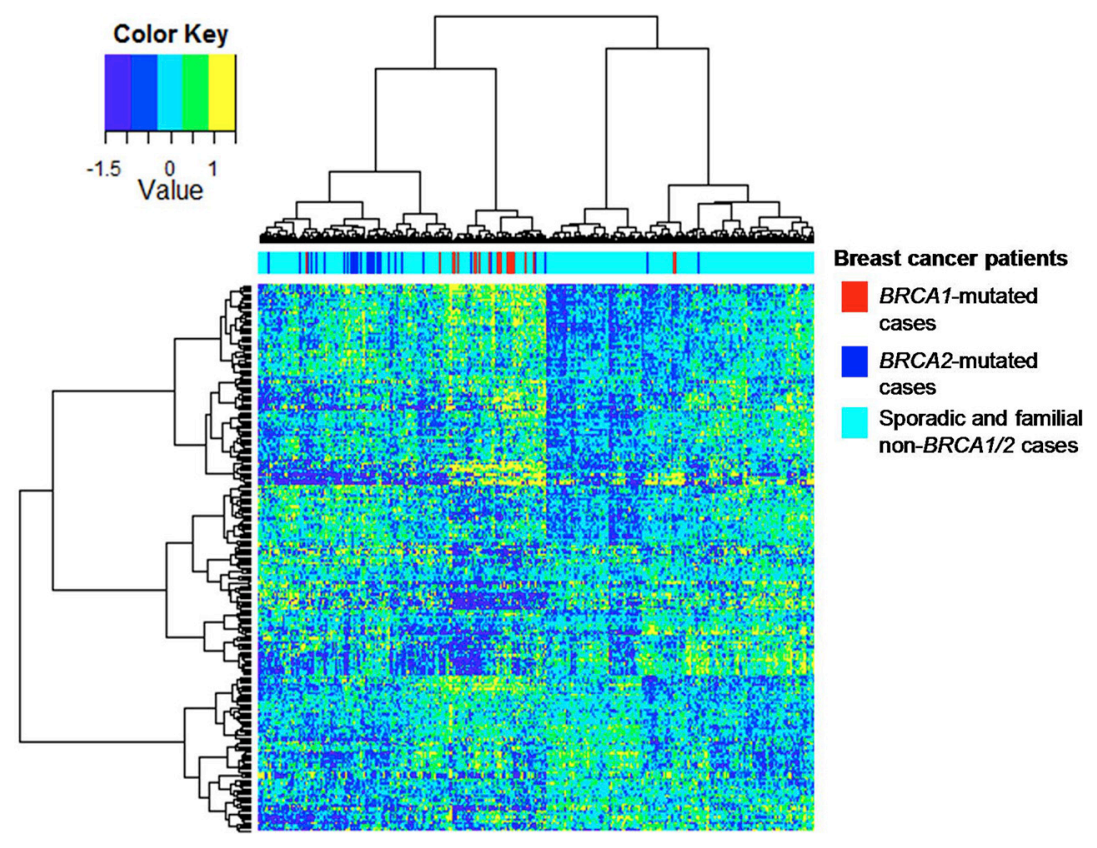

Figure 2: Hierarchical cluster analysis of the mRNA dataset for $B R C A 1 / 2$ breast carcinomas on the basis of gene expression of mapped $B \boldsymbol{R} \boldsymbol{C A 1}$-deficient proteins. Hierarchical clustering of 254 upregulated $B R C A 1$-deficient proteins showed a separation of most human $B R C A 1 / 2$-mutated breast carcinomas from sporadic breast carcinomas, when mapped to the mRNA dataset as published by Jönsson et al (Breast Cancer Res 2010). 
secretome as well as in the $B R C A 1$-deficient EVs relative to $B R C A 1$-proficient counterparts. Among them were several nuclear proteins, which have previously been identified in BRCA1-deficient breast carcinomas (TOP1, SMC3, SSRP1 and DHX9, Supplementary Figure 10). Moreover, EV-mediated release of nuclear proteins was exemplified by TOP1, which was enriched in secretome and EVs of BRCA1-deficient group and its abundance was higher in EVs than in the secretome (Supplementary Figure 11). Taken together, intracellular (nuclear) proteins of BRCA1-deficient breast tumor cells (e.g. TOP1) released through exosome-like EVs may represent putative candidates related to $B R C A 1$-deficient breast cancer.

\section{Validation of CHD3 and TOP1 in human breast carcinomas}

Two proteins highly abundant in the BRCA1deficient secretome, namely CDH3 and TOP1, were selected for validation in tumor tissue samples of breast cancer patients. $\mathrm{CDH} 3$, a plasma membrane protein, is involved in cell adhesion and has been proposed as a tissue marker in human BRCA1-deficient breast cancer as well as a serum marker in basal-like breast cancer $[14,15]$. TOP1 is a nuclear protein involved in DNA replication and was selected for validation because of its high abundance in $B R C A 1$-deficient secretome and EVs compared to BRCA1proficient counterparts. Moreover, TOP1 is present in our previously identified BRCA-like tissue signature.

Protein expression of CDH3 and TOP1 was analysed in a panel of 253 human breast carcinomas comprising 102 BRCA1-related, 49 BRCA2-related and 102 sporadic breast carcinomas. Clinical and tumor characteristics are shown in Table 1. The majority of tissue samples concerned ductal carcinomas (86-90\%). Significant differences among the three groups were noted with respect to age of histological diagnosis $(p<0.001)$, histological grade $(p=0.003)$, estrogen receptor $(p<0.001)$, progesterone receptor $(p<0.001)$ and HER2 expression $(p=0.039)$.

Receptor status (ER, PgR and HER2) was completed in 250 samples. About $74 \%$ of BRCA1-related breast carcinomas, $23 \%$ of $B R C A 2$-related breast carcinomas and $13 \%$ of sporadic breast carcinomas had triple negative phenotype lacking ER, PgR and HER2 expression $(p<$ $0.001)$. A significantly higher rate was found in $B R C A 1$ related compared with $B R C A 2$-related breast carcinomas $(p<0.001)$ as well as with sporadic carcinomas $(p<$

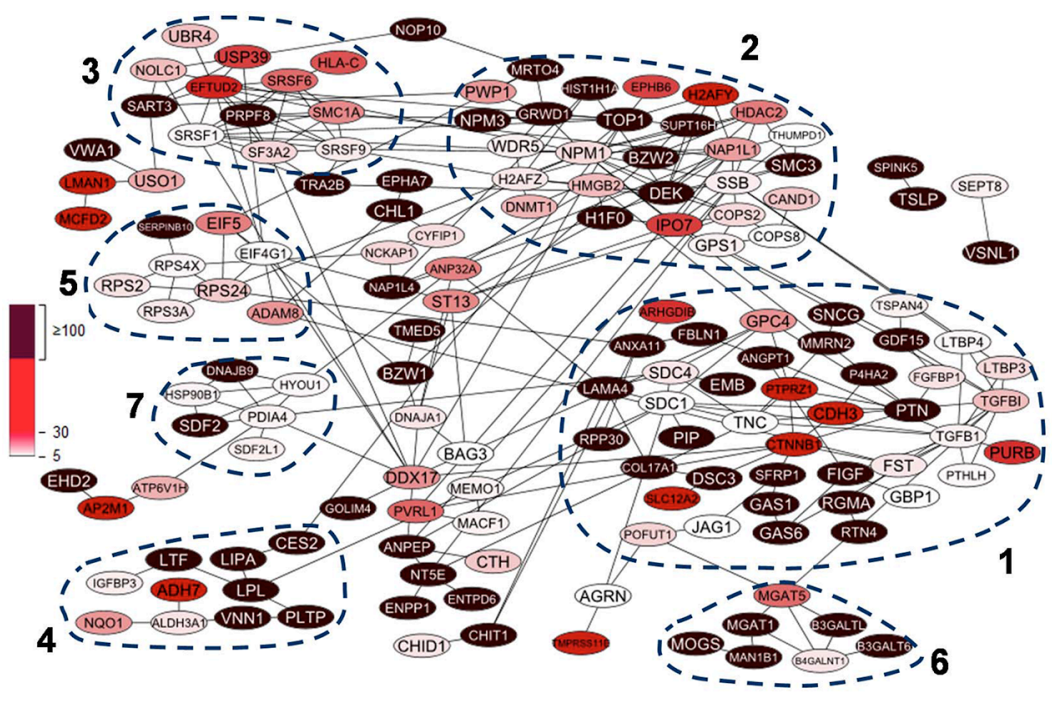

\begin{tabular}{|c|c|}
\hline \multicolumn{2}{|l|}{ Secretome subnetworks } \\
\hline \multirow{2}{*}{\multicolumn{2}{|c|}{ 1. Multicellular organismal process; extracellular region and plasma membrane }} \\
\hline & RIN4, ANGPT1, JAG1, POFU1, FGF and CINBB1 \\
\hline cell surface receptor linked signaling pattway & $\begin{array}{l}\text { SLC12A2, LTBP3, FST, JAG1, TGFB1, CINNB1, PIHLY, SDC1, SFRP1, PIN, ANGPI1, GDF15, POFUT1 and } \\
\text { FGF }\end{array}$ \\
\hline \multicolumn{2}{|l|}{ 2. Chromosome organization } \\
\hline mucheic acid metabdic process & TOP1, COPS2, HMGB2, SUPT16H, NAP1L1, DNMT1, NPMB, SSB, SMC3 and PWP1 \\
\hline \multicolumn{2}{|l|}{ 3. RNA processing } \\
\hline RNA spocing & SRSF1, SRSF6, SRSF9, PRPF8, EFTUD2, IRA2B, USP39, SMC1A and SF3A2 \\
\hline \multicolumn{2}{|l|}{ 4. Metabolic process } \\
\hline fatty acid metabolic process & LPL, UPA and ADHT \\
\hline lipid metabolic process & UPA, PLIP and LPL \\
\hline \multicolumn{2}{|l|}{ 5. Protein translation } \\
\hline translational elongation & RPS3A, RPS2, RPS4X and RPS24 \\
\hline regulation of transtation & EF4G1, EF5 and RPS4X \\
\hline \multicolumn{2}{|l|}{ 6. Carbohydrate metabolic process } \\
\hline gycosylation & B3GALT6, B3GALTL, BAGALNT1. MGAT1 and MGAT5 \\
\hline 7. Hypoxia & HYOU1 and HSP9OB1 \\
\hline
\end{tabular}

Figure 3: Protein-protein interaction network of 215 highly upregulated proteins in $B R C A 1$-deficient relative to BRCA1-proficient secretomes. Nodes represent proteins while the edges represent direct (physical) and indirect (functional) associations. Dashed lines indicate top seven most populated clusters identified by ClusterViz cluster analysis. Table shows representative biological processes of the seven clusters according to BinGO gene ontology analysis. 
Table 1: Clinical and tumor characteristics of breast carcinoma tissues

\begin{tabular}{|c|c|c|c|c|}
\hline & $\begin{array}{c}\text { Sporadic breast } \\
\text { cancer } \\
(n=102) \\
n(\%)\end{array}$ & $\begin{array}{c}B R C A 1-\text { mutated } \\
\text { breast cancer } \\
(n=102) \\
n(\%)\end{array}$ & $\begin{array}{c}B R C A 2 \text {-mutated } \\
\text { breast cancer } \\
(n=49) \\
n(\%)\end{array}$ & $P$ value \\
\hline $\begin{array}{l}\text { Tumor type } \\
\text { Ductal } \\
\text { Lobular } \\
\text { Medullary } \\
\text { Other }\end{array}$ & $\begin{array}{c}88(86) \\
10(10) \\
0 \\
4(4)\end{array}$ & $\begin{array}{c}89(87) \\
4(4) \\
4(4) \\
5(5)\end{array}$ & $\begin{array}{c}44(90) \\
3(6) \\
0 \\
2(4)\end{array}$ & 0.088 \\
\hline $\begin{array}{l}\text { Age } \\
\qquad 45 \\
\geq 45 \\
\end{array}$ & $\begin{array}{l}16(16) \\
86(84) \\
\end{array}$ & $\begin{array}{l}62(62) \\
38(38)\end{array}$ & $\begin{array}{l}18(37) \\
30(63)\end{array}$ & $<0.001$ \\
\hline $\begin{array}{c}\text { Grade } \\
1 \\
2 \\
3 \\
\end{array}$ & $\begin{array}{c}8(8) \\
32(34) \\
55(58)\end{array}$ & $\begin{array}{c}3(3) \\
17(18) \\
77(79)\end{array}$ & $\begin{array}{c}0 \\
18(39) \\
28(61) \\
\end{array}$ & 0.003 \\
\hline $\begin{array}{l}\text { Estrogen receptor } \\
\text { Positive } \\
\text { Negative }\end{array}$ & $\begin{array}{l}85(83) \\
17(17)\end{array}$ & $\begin{array}{l}27(27) \\
73(73)\end{array}$ & $\begin{array}{l}36(75) \\
12(25)\end{array}$ & $<0.001$ \\
\hline $\begin{array}{l}\text { Progesterone receptor } \\
\text { Positive } \\
\text { Negative }\end{array}$ & $\begin{array}{l}61(60) \\
41(40)\end{array}$ & $\begin{array}{l}17(17) \\
84(83)\end{array}$ & $\begin{array}{l}22(46) \\
26(54)\end{array}$ & $<0.001$ \\
\hline $\begin{array}{l}\text { HER2 } \\
\text { Positive } \\
\text { Negative }\end{array}$ & $\begin{array}{l}11(11) \\
91(89)\end{array}$ & $\begin{array}{c}2(2) \\
98(98)\end{array}$ & $\begin{array}{c}3(6) \\
45(94)\end{array}$ & 0.039 \\
\hline $\begin{array}{l}\text { TOP1 } \\
\text { Positive } \\
\text { Negative }\end{array}$ & $\begin{array}{l}24(35) \\
45(65)\end{array}$ & $\begin{array}{l}56(60) \\
38(40)\end{array}$ & $\begin{array}{l}26(59) \\
18(41)\end{array}$ & 0.004 \\
\hline $\begin{array}{l}\text { CDH3 } \\
\text { Positive } \\
\text { Negative }\end{array}$ & $\begin{array}{l}17(22) \\
62(78)\end{array}$ & $\begin{array}{l}68(76) \\
22(24)\end{array}$ & $\begin{array}{l}14(37) \\
24(63)\end{array}$ & $<0.001$ \\
\hline $\begin{array}{l}\text { TOP1 and CDH3 } \\
\text { TOP1 and CDH3 positive } \\
\text { TOP1 and/or CDH3 negative }\end{array}$ & $\begin{array}{c}5(7) \\
63(93)\end{array}$ & $\begin{array}{l}43(48) \\
46(52)\end{array}$ & $\begin{array}{c}9(24) \\
29(76)\end{array}$ & $<0.001$ \\
\hline
\end{tabular}

0.001), while no difference was found between $B R C A 2-$ related breast carcinomas and sporadic breast carcinomas $(p=0.11)$. Triple negative breast cancer appeared to be diagnosed in women of younger age $(<45$ years $)$ compared with those aged $\geq 45$ years $(58 \%$ vs $27 \%, p<0.001)$.

Representative staining results for TOP1 and CDH3 are shown in Figure 5 (high quality image of TOP1 and CDH3 staining is available in Supplementary Figure 12). The rates of TOP1-positive tumors were significantly different among the three groups $(p=0.004)$. TOP1 overexpression was mostly observed in $B R C A 1$-related $(60 \%)$ and in BRCA2-related breast carcinomas (59\%) as compared to sporadic breast carcinomas (35\%). Comparison between BRCA1-related and sporadic breast carcinomas demonstrated a significant difference in TOP1 expression $(p=0.002)$. With regard to $\mathrm{CDH} 3$, a significant difference was found among the three groups with $76 \%$ of $B R C A 1$-related, $37 \%$ of $B R C A 2$-related and
$22 \%$ of sporadic breast carcinomas being CDH3 positive $(p<0.001)$. There was a significant difference between $B R C A 1$-related and sporadic breast carcinomas in terms of CDH3-positive cases $(p<0.001)$. Of 195 breast cancer samples with TOP1 and CDH3 available, 57 samples were positive for TOP1 and $\mathrm{CDH} 3$ and 138 samples were TOP1 and/or CDH3 negative (79 positive for either of the two markers and 59 samples negative for both markers). When both markers were combined, significant differences in the rate of TOP1- and CHD3-positive tumors were found among the three groups $(p<0.001)$. Of note, the rates of TOP1 and CDH3 positivity were the highest in BRCA1related breast carcinomas (48\%) followed by $B R C A 2-$ related (24\%) and sporadic breast carcinomas $(7 \%)$.

Multiple logistic regression was performed to estimate the predictive effects of TOP1 or CDH3 for $B R C A 1 / 2$-related breast carcinomas when adjusted for triple negative breast cancer and age (Table 2). We chose to use 
Table 2: Multiple logistic regression of TOP1 and CDH3 for BRCA1/2-related breast carcinomas

\begin{tabular}{|c|c|c|c|c|}
\hline Independent variable & Beta & $\begin{array}{l}\text { Standard } \\
\text { error }\end{array}$ & $\begin{array}{c}\text { Adjusted odds ratio } \\
(95 \% \mathrm{CI})\end{array}$ & $P$ value \\
\hline $\begin{array}{l}\text { Constant } \\
\text { TNBC (yes vs no) } \\
\text { Age (<45 vs } \geq 45 \text { yrs) } \\
\text { TOP1 (positive vs negative) }\end{array}$ & $\begin{array}{c}-1.10 \\
2.09 \\
1.59 \\
1.32\end{array}$ & $\begin{array}{l}0.31 \\
0.43 \\
0.41 \\
0.37\end{array}$ & $\begin{array}{l}8.07(3.46-18.8) \\
4.88(2.18-11.0) \\
3.75(1.82-7.71)\end{array}$ & $\begin{array}{l}<0.001 \\
<0.001 \\
<0.001 \\
<0.001\end{array}$ \\
\hline $\begin{array}{l}\text { Constant } \\
\text { TNBC (yes vs no) } \\
\text { Age ( }<45 \text { vs } \geq 45 \text { yrs) } \\
\text { CDH3 (positive vs negative) }\end{array}$ & $\begin{array}{c}-0.80 \\
1.41 \\
1.46 \\
0.89\end{array}$ & $\begin{array}{l}0.23 \\
0.46 \\
0.39 \\
0.41\end{array}$ & $\begin{array}{l}4.08(1.64-10.1) \\
4.30(2.00-9.24) \\
2.44(1.08-5.49)\end{array}$ & $\begin{array}{c}<0.001 \\
<0.001 \\
<0.001 \\
0.032\end{array}$ \\
\hline $\begin{array}{l}\text { Constant } \\
\text { TNBC (yes vs no) } \\
\text { Age }(<45 \text { vs } \geq 45 \text { yrs) } \\
\text { TOP1 and CDH3 (positive vs TOP1 and/or CDH3 } \\
\text { negative) }\end{array}$ & $\begin{array}{c}-0.72 \\
1.66 \\
1.46 \\
1.62\end{array}$ & $\begin{array}{l}0.24 \\
0.43 \\
0.41 \\
0.54\end{array}$ & $\begin{array}{l}5.28(2.28-12.2) \\
4.31(1.93-9.63) \\
5.05(1.75-14.6)\end{array}$ & $\begin{array}{c}<0.001 \\
<0.001 \\
0.003 \\
0.003\end{array}$ \\
\hline
\end{tabular}

TNBC, triple-negative breast cancer.

$B R C A 1 / 2$-related breast carcinomas as an endpoint because both $B R C A 1 / 2$ mutations confer an increased risk of breast cancer. TOP1 expression was independently associated with $B R C A 1 / 2$-related breast carcinomas (adjusted odds ratio [OR] 3.75; 95\% confidence interval [95\% CI], 1.82-7.71, $p<0.001)$. Similarly, an independent association of CDH3 expression for $B R C A 1 / 2$-related breast carcinomas was found (adjusted OR 2.44; 95\% CI, 1.08-5.49, $p=0.032$ ). When TOP1 and CDH3 were combined, there was a significant association between breast carcinomas with positive TOP1 and CDH 3 and BRCA1/2 mutations (adjusted OR 5.05; 95\% CI, 1.75-14.6, $p=0.003)$.

A

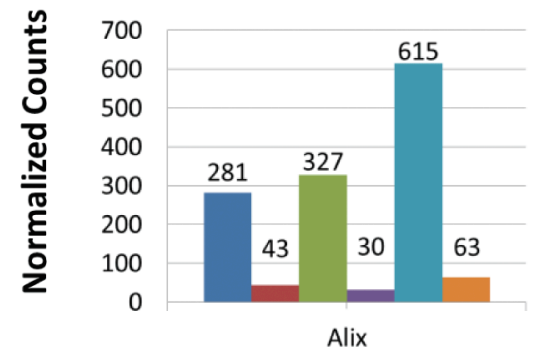

Extracellular vesicle BRCA1-def (Brca1-/- p53-/-)

Soluble secretome BRCA1-def $\left(\right.$ Brca1 $\left.^{-/-} \mathrm{p} 53^{-/-}\right)$

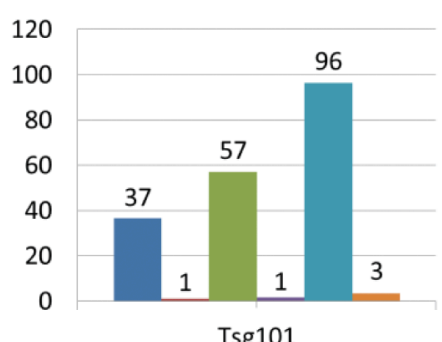

Tsg101

Extracellular vesicle BRCA1-pro (p53-/-)

Soluble secretome BRCA1-pro (p53--/)

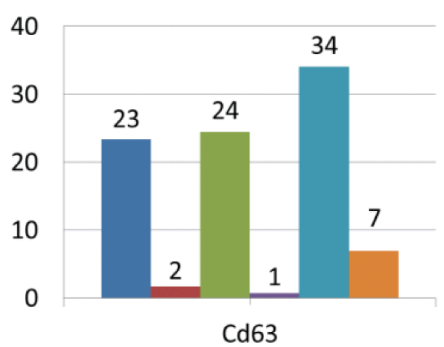

Extracellular vesicle BRCA1-pro (Cdh1//- $\mathrm{p} 53^{-/-}$)

Soluble secretome BRCA1-pro (Cdh1/- p53 $^{-/-}$)

B

BRCA1- deficient $\left(\right.$ Brca1 $1^{-t}$ p53-t)

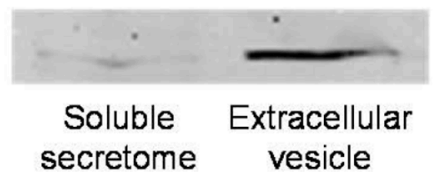

BRCA1- proficient $\left(\mathrm{p} 53^{-1}\right.$ )

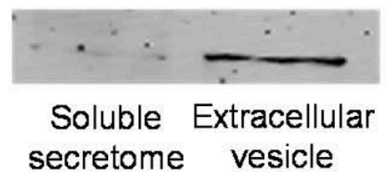

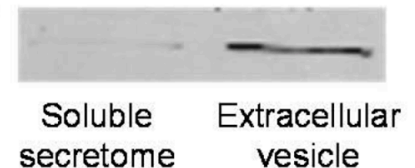

Alix

BRCA1- proficient

$\left(\mathrm{Cdh} 1^{--t} \mathrm{p} 53^{--}\right)$

Figure 4: Exosome-associated proteins identified in soluble secretome and extracellular vesicle fractions. (A) Quantification of exosome-associated proteins is presented by normalized spectral counts. (B) Western blot of Alix in soluble secretome and extracellular vesicle fractions. Cropped images of Western blot showing a common exosome marker (Alix) in soluble secretome and extracellular vesicle fractions. 


\section{DISCUSSION}

With proteomic analysis of breast tumor GEMMderived secretomes, we identified a series of released proteins associated with $B R C A 1$ status. Most of these proteins are detectable in the blood circulation according to the human plasma proteome database, suggesting their clinical usefulness in blood-based testing for the prediction of BRCA1 deficiency. Increased levels in TOP1 and CDH3 were validated in a large population-based series of breast cancer patients with a $B R C A 1 / 2$ mutation. These data merit further investigation.

The applicability of our results from murine breast tumor models to human $B R C A 1$-related breast cancer is well supported by several levels of evidence. Many $B R C A 1$-deficient candidate proteins identified play a role in DNA repair and are associated with $B R C A 1$ function. These included NPM1 [16], SMC1A [17], SMC3 [18], TOP1 [19], HMGB2 [20], DNMT1 [21], SRSF1 [22], EIF4G1 [23] and HDAC2 [24]. Further support was provided by our in silico analysis showing that $B R C A 1$ candidate proteins, when mapped to mRNA transcripts, could cluster $B R C A 1$ - and $B R C A 2$-related breast cancer cases. More importantly, we validated two candidate proteins demonstrating, in accordance with animal data, increased expression in human BRCA1related breast carcinomas. Finally, underscoring the potential use as non-invasive biomarker, 75 of protein candidates found in secretome including TOP1 and $\mathrm{CDH} 3$, are detectable in human plasma $[25,26]$. Together, our data demonstrate the potential usefulness of breast tumor GEMM-derived secretome biomarkers for non-invasive diagnosis of human BRCA1-deficient breast cancer.

Interestingly, several nuclear-specific proteins were more abundantly present in the $B R C A 1$-deficient compared to the $B R C A 1$-proficient secretome. We demonstrated that exosome-like EVs may account for non-classical secretion of these nuclear proteins. EVs and especially exosomes have previously been implicated in many cellular functions, including cell-cell communication, tumor growth, metastases formation and angiogenesis [27, 28]. EVs have also been proposed to facilitate the intercellular transfer of a spectrum of cell-type specific factors e.g. miRNA and proteins. Interestingly, the molecular content of EVs has been shown to reflect the cells of origin, thereby underscoring the potential of EV protein profiling for the use of BRCA1 detection.

In the present study, TOP1 was detected at an increased level in the BRCA1-deficient secretome and exosome-like vesicles as well as in human BRCA1related breast carcinomas. Furthermore, multiple logistic regression analysis showed that TOP1 positivity was significantly associated with $B R C A 1 / 2$ mutations (adjusted $\mathrm{OR}=3.75, p<0.001)$. This association was independent of the presence of TNBC and age suggesting that

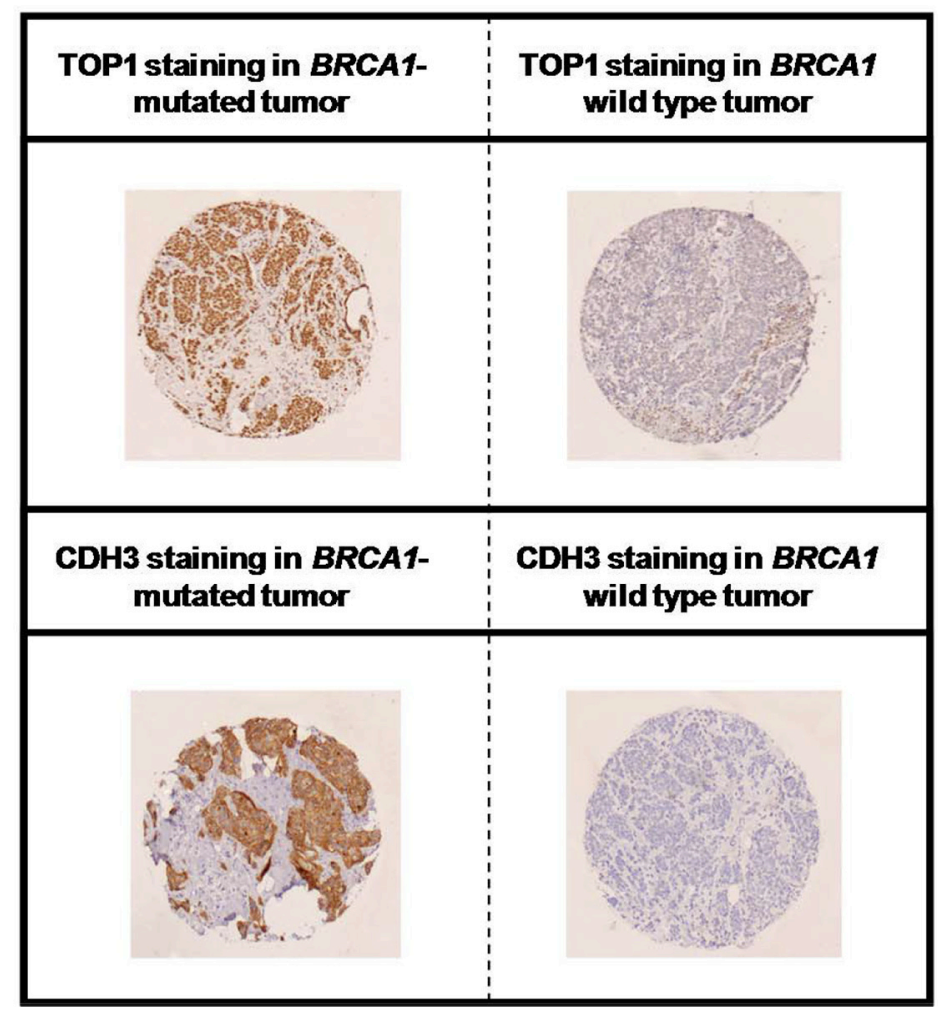

Figure 5: Immunohistochemical staining of TOP1 and CDH3 in BRCA1-deficient and proficient breast cancer. Representative positive and negative staining of TOP1 (upper panel) and CDH3 (lower panel) are shown. 
assessment of TOP1 may substantially improve prediction of $B R C A 1 / 2$ mutations, in particular in breast carcinomas with hormone-receptor positive or HER2 positive breast cancer diagnosed in women aged $\geq 45$ years. Our findings are in line with preclinical data reporting the involvement of TOP1 in DNA single-strand break repair in conjunction with BRCA1. In this regard, TOP1 has been described as a prominent target in $B R C A 1$-deficient breast cancer [29]. TOP1 inhibitors indirectly induce DNA damage and are currently under investigation for their potential in targeting tumors with homologous recombination defects [30]. Moreover, TOP1 degradation has been described to be mediated by BRCA1 and accumulation of TOP1 has been observed in case of BRCA1 dysfunction [31]. Here, we identified TOP1 to be preferentially present in BRCA1-deficient EVs. Therefore, it may be speculated that accumulated TOP1 is partly due to release via EVs.

We demonstrated increased CDH3 levels in a large panel of human BRCA1-related breast carcinomas. Similar to TOP1, increased CHD3 expression was associated with BRCA1/2-related breast carcinoma, independent of TNBC and age. These result confirmed its potential as marker for $B R C A 1 / 2$ mutations. In previous studies, an increased level of $\mathrm{CDH} 3$ has been detected in a small cohort of BRCA1deficient breast cancer [15], as well as in nipple aspirate fluid and serum obtained from women with basal-like breast tumors [14]. Gorski et al. [25] have shown that BRCA1 is a transcriptional repressor of $\mathrm{CDH} 3$, thereby providing a biological explanation for our observation of the strong presence of $\mathrm{CDH} 3$ in $B R C A 1$-deficient breast carcinomas and large abundance in $B R C A 1$-deficient secretome.

\section{MATERIALS AND METHODS}

\section{Mouse models and cell line isolation and culture}

$B R C A 1$-deficient breast tumors from $\mathrm{K} 14 \mathrm{Cre} ; \mathrm{BrCa}^{-1-} ; \mathrm{p53}^{-/-}$GEMMs resemble human BRCA1deficient breast cancer as determined by histopathology and genotyping. BRCA1-proficient breast tumors from $\mathrm{K} 14 \mathrm{Cre} ; \mathrm{p5}^{-/-}$GEMMs resemble human sporadic basal-like breast cancer, whereas BRCA1-proficient

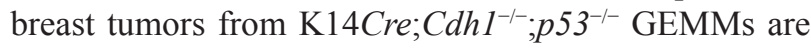
histopathologically similar to human pleomorphic lobular breast cancer [10].

Primary breast tumor cells were isolated from tumorbearing GEMMs as described in detail elsewhere [32]. Cell lines were cultured at $37^{\circ} \mathrm{C}$ and $5 \% \mathrm{CO}_{2}$ atmosphere in DMEM/F12-GlutaMAX medium (Gibco) supplemented with $10 \%$ fetal calf serum (FCS), $1 \%$ penicillinstreptomycin (Lonza), $5 \mu \mathrm{g} / \mathrm{ml}$ insulin, $5 \mathrm{ng} / \mathrm{ml}$ epidermal growth factor (Life Technologies) and $5 \mathrm{ng} / \mathrm{ml}$ cholera toxin. Serum-free medium contains the above-mentioned supplements without FCS. All animal experiments were approved by the animal research committee of the Netherlands Cancer Institute.

\section{Preparation of breast tumor cell line secretomes}

Cell line secretomes were prepared as described before [11]. In brief, tumor cells were grown until 70-80\% confluency and incubated in serum-free medium overnight for 22-24 h. The conditioned medium (referred to as secretome) was removed from cell debris and concentrated to a final volume of $\sim 50 \mu \mathrm{L}$ using $3 \mathrm{kDa}$ cutoff spin filter (Millipore). The samples supplemented with Sodium Dodecyl Sulfate (SDS) sample buffer containing $100 \mathrm{mM}$ dithiotreitol were stored at $-80^{\circ} \mathrm{C}$ until further analysis.

\section{Extracellular vesicles isolation}

Isolation of EVs was performed by ultracentrifugation according to an established method $[33,34]$. In short, $\sim 5$ $\mathrm{mL}$ concentrated secretome was subjected to differential centrifugation steps at $12,000 \times g$ for $1 \mathrm{~h}$ and at $110,000 \times$ $g$ for $2 \mathrm{~h}$ using a Beckman SW40TI rotor. The supernatant, further referred to as the soluble protein fraction, was collected and the EV pellet was centrifuged at 110,000 $\times g$ for another $2 \mathrm{~h}$ and suspended in SDS sample buffer before storage at $-80^{\circ} \mathrm{C}$. The soluble protein fraction was concentrated and stored at $-80^{\circ} \mathrm{C}$ supplemented with SDS sample buffer.

\section{Western blot}

$\mathrm{EV}$ and soluble protein fractions were immunoblotted with anti-Alix primary antibody (3A9, Cell signaling), followed by secondary antibody conjugated with IRDye 680 (Rockland). Fluorescent signals were detected with an Odyssey infrared imaging system (LICOR Biosciences).

\section{Proteomics by tandem mass spectrometry and database searching}

Proteins from secretomes or EVs were fractionated by one-dimensional electrophoresis followed by trypsin in-gel protein digestion and nanocapillary liquid chromatography-tandem mass spectrometry (GeLC-MS/ MS) [11]. Secretome tryptic digests were measured on an Ultimate 3000 nanoLC system (Dionex LC-Packings) on-line coupled to the LTQ-FT hybrid mass spectrometer (Thermo Fisher) using a top5 MS/MS method. EV tryptic digests were measured on a Q Exactive mass spectrometer (Thermo Fisher) coupled to a Ultimate 3000 nanoLC system (Dionex LC-Packings). The raw MS/MS data were processed as described before [8].

\section{Tissue microarray and immunohistochemistry}

The study group comprised 253 cases of human breast carcinomas, among which were 102 BRCA1, $49 B R C A 2$ germline mutation-related cases and 102 breast cancer cases not known to have a $B R C A 1 / 2$ 
mutation (further denoted as "sporadic"). Four $\mu \mathrm{m}$ thick sections were stained with hematoxylin and eosin for histopathology. Tumor type was assessed according to WHO and tumors were graded according to the Nottingham grading system. Tissue microarrays were constructed and stained for estrogen receptor (ER, 1:100, DAKO), progesterone receptor (PR, 1:100, DAKO), human epidermal growth factor receptor-2 (HER2, 1:100, Thermo Scientific [Neomarkers]), TOP1 (1:100, Abcam) and CDH3 (extracellular domain, 1:400, BD Biosciences, Pharmingen). Appropriate positive and negative controls were used throughout.

All specimens were scored by a single pathologist (PJvD), who was blinded to the origin of tumors. For ER and PR, the percentage of positive nuclei was scored. Samples with $\geq 10 \%$ immunopositive malignant cells were classified as ER or PR positive. For HER2 and $\mathrm{CDH} 3$, membranous staining was scored according to the DAKO scoring system as $0,1+, 2+$ and $3+$, considering HER2 $3+$ and CDH3 $1+, 2+$ and $3+$ cases as positive. For TOP1, the percentage of positive nuclei and the intensity of staining were scored. The product of the percentage of positive nuclei and the intensity of staining was calculated and cases above 170 were classified as positive. Since we used archival pathology material, which does not interfere with patient care and does not involve the physical involvement of the patient, no ethical approval was required according to institutional and Dutch regulations under an opt out system (reviewed by van Diest et al. [35]).

\section{Data analysis}

For each protein, spectral counts were normalized for the total spectral counts in each sample. The normalized spectral counts were used for further comparative analyses. Differences in relative protein abundance, expressed as normalized spectral count, between BRCA1-deficient and -proficient GEMMs were analyzed using the beta binomial test [36-38]. $P<0.05$ was considered statistically significant. Hierarchical unsupervised clustering was carried out on all identified proteins. Associations between immunohistochemistry (IHC) expression of proteins were tested by Pearson's Chi-square test. Multiple logistic regression was used to estimate the predictive effects of candidate biomarkers for identifying mutation carriers while adjusting for confounding factors. All statistical analyses were carried out with SPSS and R.

The clinical relevance of protein candidates was evaluated by analyzing the gene expression dataset containing mRNA expression of BRCA1/2-related and sporadic breast carcinomas as published by Jönnson et al. [12]. As clustering parameters for the gene expression dataset, we used a Spearman rank correlation in combination with the Ward's distance. mRNA levels of candidate proteins between $B R C A 1 / 2$-deficient breast cancer and sporadic breast cancer were evaluated with Mann-Whitney $U$ test using $P<0.1$ as an arbitrary cutoff. To identify putative blood-based markers, protein candidates were evaluated in different human plasma proteome databases $[39,40]$.

Ingenuity pathway analysis software (Ingenuity Systems) and DAVID tool [41] were used to analyze biological functions and deregulated pathways in BRCA1deficient breast cancer. SignalP and SecretomeP were used to predict proteins potentially undergoing classical and non-classical secretion [13, 42]. Cytoscape (version 2.7.2) [43] and STRING tool (version 9.0) [44] were used to analyze protein interactions as well as for network analysis. Cytoscape ClusterViz plugin was employed to identify clusters of biological networks [45].

\section{CONCLUSIONS AND OUTLOOK}

Our study provides a promising set of secreted or excreted proteins that could find use in early non-invasive detection of tumors that arise in BRCA1 mutation carriers and that might support management of treatment choice. Further validation of the detection of released biomarker proteins in body fluids, such as blood or nipple aspirate fluid, is a vital aspect to be resolved for future clinical applications. At present, this validation is hampered by limited availability of sensitive ELISA assays for the majority of candidate protein biomarkers. Therefore, we here applied immunohistochemistry for verification of increased expression of TOP1 and CDH3 in BRCA1deficient breast carcinomas. New multiplex technologies, such as targeted mass spectrometry, may provide better opportunities for future large-scale validation in biofluids. Importantly, up to $75 \%$ of the BRCA1 deficiencyassociated secretome proteins are detectable in blood, thereby underscoring the value of our proteomic strategy. Future studies are warranted to assess the non-invasive diagnostic power of these proteins for early detection of breast tumors in cohorts of BRCA1 mutation carriers.

\section{CONFLICTS OF INTEREST}

\section{None.}

\section{GRANT SUPPORT}

SWL was supported by the Center for Translational Molecular Medicine (CTMM-MAMMOTH) and has received an educational grant from Roche. EB has received research support funding from Roche and Novartis. JEJ and SR were supported by the Netherlands Organization for Scientific Research (NWO-Toptalent, NWO-VIDI 91711302) and the Dutch Cancer Society (NKI 20115220). All other authors declare no conflicts of interest. The VUmc-Cancer Center Amsterdam is acknowledged for support for the proteomics infrastructure. 


\section{REFERENCES}

1. Pinsky RW, Helvie MA. Mammographic breast density: effect on imaging and breast cancer risk. J Natl Compr Canc Netw. 2010; 8:1157-1164.

2. Checka CM, Chun JE, Schnabel FR, Lee J, Toth H. The relationship of mammographic density and age: implications for breast cancer screening. AJR Am J Roentgenol. 2012; 198:W292-W295.

3. Boyd NF, Guo H, Martin LJ, Sun L, Stone J, Fishell E, Jong RA, Hislop G, Chiarelli A, Minkin S, Yaffe MJ. Mammographic density and the risk and detection of breast cancer. N Engl J Med. 2007; 356:227-236.

4. Warner E, Hill K, Causer P, Plewes D, Jong R, Yaffe M, Foulkes WD, Ghadirian P, Lynch H, Couch F, Wong J, Wright F, Sun P et al. Prospective study of breast cancer incidence in women with a BRCA1 or BRCA2 mutation under surveillance with and without magnetic resonance imaging. J Clin Oncol. 2011; 29:1664-1669.

5. Kriege M, Brekelmans CT, Boetes C, Besnard PE, Zonderland HM, Obdeijn IM, Manoliu RA, Kok T, Peterse H, Tilanus-Linthorst MM, Muller SH, Meijer S, Oosterwijk JC et al. Efficacy of MRI and mammography for breast-cancer screening in women with a familial or genetic predisposition. N Engl J Med. 2004; 351:427-437.

6. Rijnsburger AJ, Obdeijn IM, Kaas R, Tilanus-Linthorst MM, Boetes C, Loo CE, Wasser MN, Bergers E, Kok T, Muller SH, Peterse H, Tollenaar RA, Hoogerbrugge N et al. BRCA1-associated breast cancers present differently from BRCA2-associated and familial cases: long-term follow-up of the Dutch MRISC Screening Study. J Clin Oncol. 2010; 28:5265-5273.

7. Schaaij-Visser TB, de Wit M, Lam SW, Jimenez CR. The cancer secretome, current status and opportunities in the lung, breast and colorectal cancer context. Biochim Biophys Acta. 2013; 1834:2242-2258.

8. Warmoes M, Jaspers JE, Pham TV, Piersma SR, Oudgenoeg G, Massink MP, Waisfisz Q, Rottenberg S, Boven E, Jonkers J, Jimenez CR. Proteomics of mouse BRCA1-deficient mammary tumors identifies DNA repair proteins with potential diagnostic and prognostic value in human breast cancer. Mol Cell Proteomics. 2012; 11:M111.

9. Liu X, Holstege H, van der Gulden H, Treur-Mulder M, Zevenhoven J, Velds A, Kerkhoven RM, van Vliet MH, Wessels LF, Peterse JL, Berns A, Jonkers J. Somatic loss of BRCA1 and p53 in mice induces mammary tumors with features of human BRCA1-mutated basal-like breast cancer. Proc Natl Acad Sci USA. 2007; 104:12111-12116.

10. Derksen PW, Liu X, Saridin F, van der Gulden H, Zevenhoven J, Evers B, van Beijnum JR, Griffioen AW, Vink J, Krimpenfort P, Peterse JL, Cardiff RD, Berns A et al. Somatic inactivation of E-cadherin and p53 in mice leads to metastatic lobular mammary carcinoma through induction of anoikis resistance and angiogenesis. Cancer Cell. 2006; 10:437-449.
11. Piersma SR, Labots M, Verheul HM, Jimenez CR. Strategies for kinome profiling in cancer and potential clinical applications: chemical proteomics and array-based methods. Anal Bioanal Chem. 2010; 397:3163-3171.

12. Jonsson G, Staaf J, Vallon-Christersson J, Ringner M, Holm K, Hegardt C, Gunnarsson H, Fagerholm R, Strand C, Agnarsson BA, Kilpivaara O, Luts L, Heikkila P et al.Genomic subtypes of breast cancer identified by array-comparative genomic hybridization display distinct molecular and clinical characteristics. Breast Cancer Res. 2010; 12:R42.

13. Bendtsen JD, Jensen LJ, Blom N, von Heijne G, Brunak S. Feature-based prediction of non-classical and leaderless protein secretion. Protein Eng Des Sel. 2004; 17:349-356.

14. Mannello F, Tonti GA, Medda V, Pederzoli A, Sauter ER. Increased shedding of soluble fragments of P-cadherin in nipple aspirate fluids from women with breast cancer. Cancer Sci. 2008; 99:2160-2169.

15. Arnes JB, Brunet JS, Stefansson I, Begin LR, Wong N, Chappuis PO, Akslen LA, Foulkes WD. Placental cadherin and the basal epithelial phenotype of BRCA1-related breast cancer. Clin Cancer Res. 2005; 11:4003-4011.

16. Koike A, Nishikawa H, Wu W, Okada Y, Venkitaraman AR, Ohta T. Recruitment of phosphorylated NPM1 to sites of DNA damage through RNF8-dependent ubiquitin conjugates. Cancer Res. 2010; 70:6746-6756.

17. Schar P, Fasi M, Jessberger R. SMC1 coordinates DNA double-strand break repair pathways. Nucleic Acids Res. 2004; 32:3921-3929.

18. Yazdi PT, Wang Y, Zhao S, Patel N, Lee EY, Qin J. SMC1 is a downstream effector in the ATM/NBS1 branch of the human S-phase checkpoint. Genes Dev. 2002; 16:571-582.

19. Tomicic MT, Kaina B. Topoisomerase degradation, DSB repair, p53 and IAPs in cancer cell resistance to camptothecin-like topoisomerase I inhibitors. Biochim Biophys Acta. 2013; 1835:11-27.

20. Stros M, Polanska E, Struncova S, Pospisilova S. HMGB1 and HMGB2 proteins up-regulate cellular expression of human topoisomerase IIalpha. Nucleic Acids Res. 2009; 37:2070-2086.

21. Wang KY, James Shen CK. DNA methyltransferase Dnmt1 and mismatch repair. Oncogene. 2004; 23:7898-7902.

22. Burgess RC, Misteli T, Oberdoerffer P. DNA damage, chromatin, and transcription: the trinity of aging. Curr Opin Cell Biol. 2012; 24:724-730.

23. Badura M, Braunstein S, Zavadil J, Schneider RJ. DNA damage and eIF4G1 in breast cancer cells reprogram translation for survival and DNA repair mRNAs. Proc Natl Acad Sci USA. 2012; 109:18767-18772.

24. Miller KM, Tjeertes JV, Coates J, Legube G, Polo SE, Britton S, Jackson SP. Human HDAC1 and HDAC2 function in the DNA-damage response to promote DNA nonhomologous end-joining. Nat Struct Mol Biol. 2010; 17:1144-1151. 
25. Gorski JJ, James CR, Quinn JE, Stewart GE, Staunton KC, Buckley NE, McDyer FA, Kennedy RD, Wilson RH, Mullan PB, Harkin DP. BRCA1 transcriptionally regulates genes associated with the basal-like phenotype in breast cancer. Breast Cancer Res Treat. 2010; 122:721-731.

26. Sennels L, Salek M, Lomas L, Boschetti E, Righetti PG, Rappsilber J. Proteomic analysis of human blood serum using peptide library beads. J Proteome Res. 2007; 6:40554062 .

27. Vlassov AV, Magdaleno S, Setterquist R, Conrad R. Exosomes: current knowledge of their composition, biological functions, and diagnostic and therapeutic potentials. Biochim Biophys Acta. 2012; 1820:940-948.

28. Mathivanan S, Ji H, Simpson RJ. Exosomes: extracellular organelles important in intercellular communication. J Proteomics. 2010; 73:1907-1920.

29. Zander SA, Kersbergen A, van der Burg E, de WN, van TO, Gunnarsdottir S, Jaspers JE, Pajic M, Nygren AO, Jonkers J, Borst P, Rottenberg S. Sensitivity and acquired resistance of BRCA1; p53-deficient mouse mammary tumors to the topoisomerase I inhibitor topotecan. Cancer Res. 2010; 70:1700-1710.

30. Vollebergh MA, Jonkers J, Linn SC. Genomic instability in breast and ovarian cancers: translation into clinical predictive biomarkers. Cell Mol Life Sci 2012; 69:223-245.

31. Sordet O, Larochelle S, Nicolas E, Stevens EV, Zhang C, Shokat KM, Fisher RP, Pommier Y. Hyperphosphorylation of RNA polymerase II in response to topoisomerase I cleavage complexes and its association with transcriptionand BRCA1-dependent degradation of topoisomerase I. J Mol Biol. 2008; 381:540-549.

32. Silver DP, Dimitrov SD, Feunteun J, Gelman R, Drapkin R, Lu SD, Shestakova E, Velmurugan S, Denunzio N, Dragomir S, Mar J, Liu X, Rottenberg S et al. Further evidence for BRCA1 communication with the inactive $\mathrm{X}$ chromosome. Cell. 2007; 128:991-1002.

33. Chiasserini D, van Weering JR, Piersma SR, Pham TV, Malekzadeh A, Teunissen CE, de WH, Jimenez CR. Proteomic analysis of cerebrospinal fluid extracellular vesicles: a comprehensive dataset. J Proteomics. 2014; 106:191-204.

34. Tauro BJ, Greening DW, Mathias RA, Ji H, Mathivanan S, Scott AM, Simpson RJ. Comparison of ultracentrifugation, density gradient separation, and immunoaffinity capture methods for isolating human colon cancer cell line LIM1863-derived exosomes. Methods. 2012; 56:293-304.

35. van Diest PJ. No consent should be needed for using leftover body material for scientific purposes. For. BMJ. 2002; 325:648-651.
36. Old WM, Meyer-Arendt K, Aveline-Wolf L, Pierce KG, Mendoza A, Sevinsky JR, Resing KA, Ahn NG. Comparison of label-free methods for quantifying human proteins by shotgun proteomics. Mol Cell Proteomics 2005; 4:1487-1502.

37. Pham TV, Piersma SR, Warmoes M, Jimenez CR. On the beta-binomial model for analysis of spectral count data in label-free tandem mass spectrometry-based proteomics. Bioinformatics. 2010; 26:363-369.

38. Piersma SR, Fiedler U, Span S, Lingnau A, Pham TV, Hoffmann S, Kubbutat MH, Jimenez CR. Workflow comparison for label-free, quantitative secretome proteomics for cancer biomarker discovery: method evaluation, differential analysis, and verification in serum. J Proteome Res. 2010; 9:1913-1922.

39. Omenn GS, States DJ, Adamski M, Blackwell TW, Menon R, Hermjakob H, Apweiler R, Haab BB, Simpson RJ, Eddes JS, Kapp EA, Moritz RL, Chan DW et al. Overview of the HUPO Plasma Proteome Project: results from the pilot phase with 35 collaborating laboratories and multiple analytical groups, generating a core dataset of 3020 proteins and a publicly-available database. Proteomics. 2005; 5:3226-3245.

40. Muthusamy B, Hanumanthu G, Suresh S, Rekha B, Srinivas D, Karthick L, Vrushabendra BM, Sharma S, Mishra G, Chatterjee P, Mangala KS, Shivashankar HN, Chandrika KN et al. Plasma Proteome Database as a resource for proteomics research. Proteomics. 2005; 5:3531-3536.

41. Huang DW, Sherman BT, Tan Q, Kir J, Liu D, Bryant D, Guo Y, Stephens R, Baseler MW, Lane HC, Lempicki RA. DAVID Bioinformatics Resources: expanded annotation database and novel algorithms to better extract biology from large gene lists. Nucleic Acids Res. 2007; 35:W169-W175.

42. Petersen TN, Brunak S, von Heijne G, Nielsen H. SignalP 4.0: discriminating signal peptides from transmembrane regions. Nat Methods. 2011; 8:785-786.

43. Shannon P, Markiel A, Ozier O, Baliga NS, Wang JT, Ramage D, Amin N, Schwikowski B, Ideker T. Cytoscape: a software environment for integrated models of biomolecular interaction networks. Genome Res. 2003; 13:2498-2504.

44. Jensen LJ, Kuhn M, Stark M, Chaffron S, Creevey C, Muller J, Doerks T, Julien P, Roth A, Simonovic M, Bork P, von MC. STRING 8-a global view on proteins and their functional interactions in 630 organisms. Nucleic Acids Res. 2009; 37:D412-D416.

45. Bader GD, Hogue CW. An automated method for finding molecular complexes in large protein interaction networks. BMC Bioinformatics. 2003; 4:2. 